This item was submitted to Loughborough's Research Repository by the author.

Items in Figshare are protected by copyright, with all rights reserved, unless otherwise indicated.

\title{
Design guidelines for pregnant occupant safety
}

PLEASE CITE THE PUBLISHED VERSION

http://dx.doi.org/10.1243/095440705X28402

\section{PUBLISHER}

(c) The authors. Published by SAGE Journals

\section{VERSION}

AM (Accepted Manuscript)

\section{PUBLISHER STATEMENT}

This work is made available according to the conditions of the Creative Commons Attribution-NonCommercialNoDerivatives 4.0 International (CC BY-NC-ND 4.0) licence. Full details of this licence are available at: https://creativecommons.org/licenses/by-nc-nd/4.0/

\section{LICENCE}

CC BY-NC-ND 4.0

\section{REPOSITORY RECORD}

Acar, B. Serpil, and Alix M. Weekes. 2019. “Design Guidelines for Pregnant Occupant Safety”. figshare. https://hdl.handle.net/2134/25642. 


\title{
Design guidelines for pregnant occupant safety
}

\author{
B S Acar* and A M Weekes
}

Department of Computer Science, Loughborough University, Loughborough, UK

\begin{abstract}
During pregnancy a woman's body undergoes a considerable change in size and shape, and this can impact upon her safety during car travel. The two main issues are proper seat belt use and positioning, and steering wheel clearance. A comprehensive analysis of the questionnaire responses by pregnant women and anthropometric measurements demonstrates that the difficulties experienced can be explained by the physical changes and interactions throughout the body during gestation. Analysis of the anthropometry of pregnant women highlights that many pregnant users could easily be excluded from designs inadvertently if the design is based on males or non-pregnant females. Thus incorporation of pregnant women's anthropometry into automotive design could reduce the exclusion rates and alleviate problems. This paper presents guidelines for the automotive industry generated from experiences and anthropometry of pregnant women, with the aim of improving safety for pregnant car occupants.
\end{abstract}

Keywords: pregnant, occupant, safety, automotive design, guidelines

\section{INTRODUCTION}

During pregnancy a woman's body undergoes a wide variety of physical changes and this can impact upon her safety during driving and car travel. Recent reports from the USA have shown that the biggest cause of abdominal trauma is the automotive collision. Baerga-Varela et al. [1] and Cosi et al. [2] found that automobile trauma was the maternal trauma mechanism for 64 and 65 per cent respectively of cases. Abdominal trauma caused by impact to the abdomen can result in placental abruption, fetal injury and/or death, feto-maternal transfusion, and onset of labour [3-6].

The correct seat belt position for pregnant women described by the Department for Transport (DFT) in the UK [7], and the National Highway Traffic Safety Administration (NHTSA) in the USA [8], is that the lap strap should go across the hips, fitting comfortably under the bump, while the diagonal strap should be placed between the breasts and around the bump [7]. Regarding the use of seat belts in pregnancy, research has shown that the pregnant woman and

* Corresponding author: Department of Computer Science, Loughborough University, Loughborough LE11 3TU, UK. email: S.Acar@lboro.ac.uk her fetus are at increased risk during a collision if the seat belt is not worn [9], or only the lap belt is used $[\mathbf{1 0}, \mathbf{1 1}]$, or if it is incorrectly positioned $[\mathbf{1 0}, \mathbf{1 2}]$.

Klinich et al. [13] reported that only 31 of their 43 women (72 per cent) were using the seat belt in their study entitled 'Investigations of crashes involving pregnant occupants', but did not state how the seat belt was positioned. Johnson and Pring [14] reported that in 1998, from 200 women attending an antenatal clinicin York(UK), 98 per cent were wearing the seat belt, but only 48 per cent had it correctly positioned.

There is a lack of research into why pregnant women do not position the belt correctly. Improving seat belt use and its safe positioning can help to improve the safety of pregnant women, and many papers have called for provision of information about seat belt legislation and guidelines for pregnant women to be increased [14-17]. However, these are all focused on disseminating information through medical channels, and this approach will be more

effective if combined with driver behaviour [18]. Another source of risk is proximity to the steering wheel through direct impact with the wheel [19], or possibly a deployed airbag although the level of this risk is unproven.

DeLeonardisetal. [20] showed that shorterwomen are at increased risk of injury owing to proximity 
to the steering wheel, and Dobson and Baird [21] suggest that seat position is directly related to height. University of Michigan Transport Research Institute research showed that, as pregnancy progresses, the abdomen protrudes closer to the steering wheel $[19,22,23]$; hence risk is increased in pregnancy because of the decreased distance from the steering wheel [24]. Klinich et al. [25] showed that pregnant women do not adjust their fore/aft seat position or seat back angle during pregnancy to compensate for increased abdominal protrusion.

There is a dearth of reseach investigating anthropometric changes to all body parts, or how different regions of the body interact. The study by Yamana et al. [26] was originally aimed at garment design, and it includes few measurements that are applicable to automotive design. Yamana et al. measured 44 dimensions of 520 pregnant women from the second to tenth month of pregnancy.

A project funded by the Engineering and Physical Sciences Research Council, UK (EPSRC), entitled 'Automotive design: incorporating the needs of pregnant women' started in 2001 at Loughborough University. This research addresses the problems associated with changes during pregnancy on the entire body and driving. The data set collected in this research was selected specifically for use in automotive design. The aim of this project is to provide pregnant women's anthropometric measurements and guidelines to designers in automotive industry.

This paper investigates the physical changes during pregnancy and their resultant effect upon the safety of pregnant car occupant and her fetus. The data sets are collected with a broad understanding that physical changes to a pregnant woman are not limited to the abdominal region. These data sets are compared with non-pregnant data to study possible exclusion percentiles. In particular, two main safety issues, namely the use and positioning of the seat belt during pregnancy and the proximity to the steering wheel, have been focused on and the guidelines for the automotive industry are generated.

\section{METHOD}

Two methods of data collection were used in this study: a questionnaire and anthropometric measurements.

The pregnant women answered a 'pregnancy and driving questionnaire' in an interview or by self-completion. At the time of writing, 450 sets of questionnaire responses had been processed. The questionnaire can be found for online completion at http://pregnantdriver.lboro.ac.uk in fivelanguages (English, Spanish, Italian, Turkish, and French). Responses have been received from around the world with the majority being from the UK (63 per cent), and the remainder from the USA and Canada (19 per cent), from other European countries (10 per cent), and from other countries of the world (8 per cent). The pregnant women were reminded repeatedly to compare their experiences during pregnancy with when they were not pregnant. Questions about all aspects of car travel both as drivers and as passengers were included in the questionnaire. In particular, the questions about seat belt use, and steering wheel clearance, were asked to gain understanding in trends in driving during pregnancy.

The standard anthropometric postures [27] were adapted for pregnant women by the present authors and a series of anthropometric measurements were taken. At the time of writing, 100 sets of measurements were recorded. Volunteers wore light clothing and removed their shoes, and the equipment used included weight scales, a stadiometer, a digital vernier calliper, a tape measure, and an anthropometer. Women were recruited in twolocations in the UK: Loughborough University, and the Luton and Dunstable Hospital National Health Service Trust. The measurements of the hip, abdominal, and chest regions (illustrated in Fig. 1) were taken for better understanding of how physical changes can impact upon safe driving in pregnancy.

The anthropometric data analysis focused on comparing the UK pregnant women in the sample against data from the literature [28] for UK males and non-pregnant females. The gestation levels of the pregnant women recruited to this study are summarized in Table 1 . The majority of these women normally occupy the driver's seat and occasionally use the front or rear passenger seats; in a few cases the normal occupant position is unknown. For both the anthropometric and questionnaire data the overall trends were examined. Extreme cases were also examined to highlight the scale of the risk for these pregnant women. Guidelines for automotive designers were generated from this data analysis, and from specific comments from pregnant women.

\section{USE AND POSITIONING OF SEAT BELTS}

Research has proven that wearing the seat belt and ensuring that it is correctly positioned are of vital importance to the safety of pregnant women and 


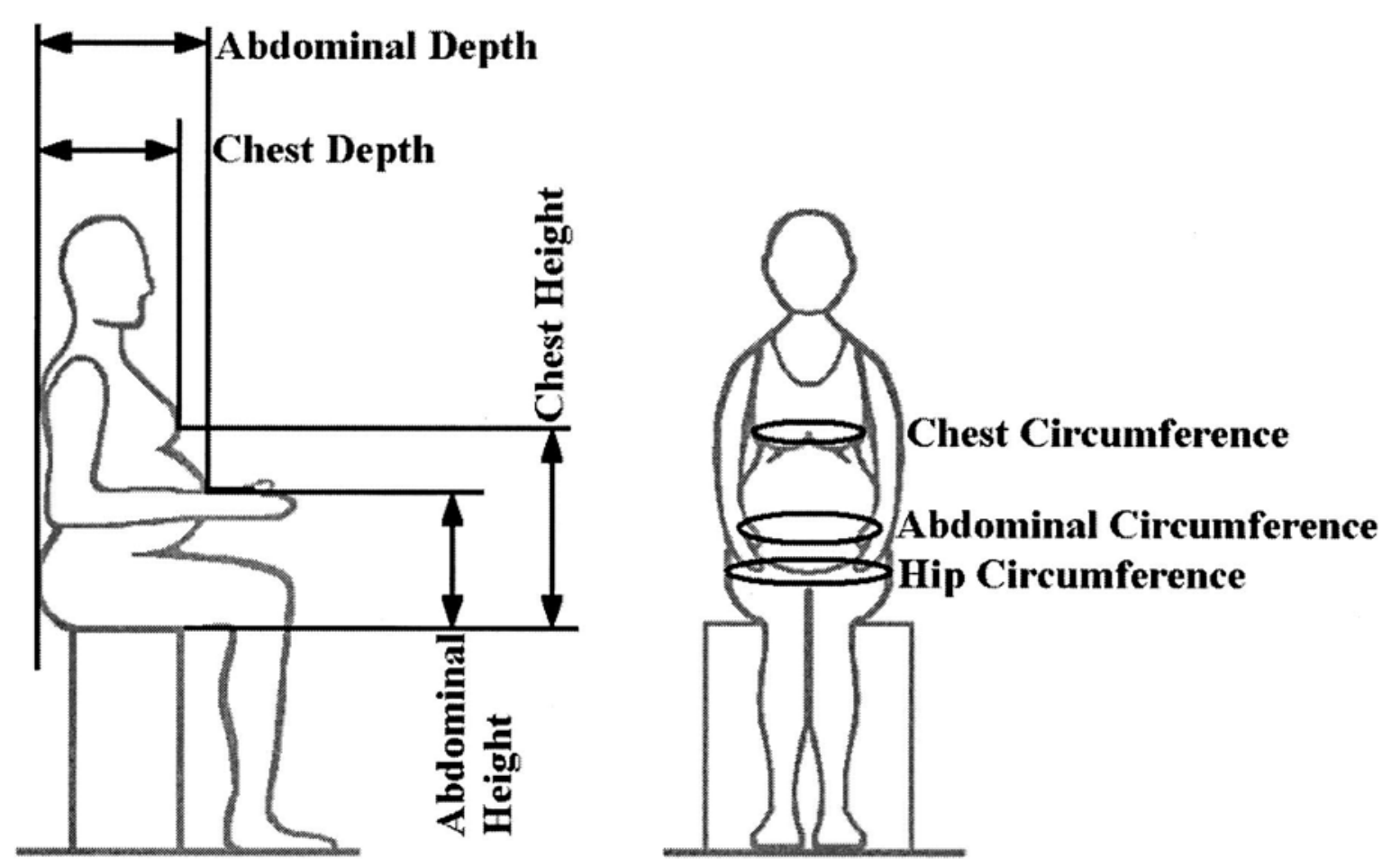

Fig. 1 Anthropometric measurements recorded from pregnant women with particular relevance to safety aspects of car travel

Table 1 Pregnancy and driving details of the sample of pregnant women: first, second and third trimesters

\begin{tabular}{|c|c|c|c|}
\hline & $\begin{array}{l}\text { First trimester } \\
\text { (weeks 0-12) }\end{array}$ & $\begin{array}{l}\text { Second trimester } \\
\text { (weeks 13-28) }\end{array}$ & $\begin{array}{l}\text { Third trimester } \\
\text { (weeks 29-40+) }\end{array}$ \\
\hline \multicolumn{4}{|l|}{ Pregnancy and driving questionnaire } \\
\hline Number of volunteers & 34 women & 159 women & 257 women \\
\hline Mean week of pregnancy & 8.5 weeks & 21.6 weeks & 35.2 weeks \\
\hline Standard deviation week of pregnancy & 2.3 weeks & 4.4 weeks & 3.3 weeks \\
\hline Driver & 32 women & 156 women & 243 women \\
\hline Non-driver and unknown & 2 women & 2 and 1 women & 5 and 9 women \\
\hline \multicolumn{4}{|l|}{ Anthropometric measurements } \\
\hline Number of volunteers & 0 & 35 women & 65 women \\
\hline Mean week of pregnancy & $\mathrm{N} / \mathrm{A}$ & 21.6 weeks & 35.5 weeks \\
\hline Standard deviation week of pregnancy & $\mathrm{N} / \mathrm{A}$ & 4.5 weeks & 2.8 weeks \\
\hline Driver & $\mathrm{N} / \mathrm{A}$ & 34 women & 52 women \\
\hline Non-driver and unknown & $\mathrm{N} / \mathrm{A}$ & 0 and 1 women & 4 and 9 women \\
\hline
\end{tabular}

N/A, not applicable.

their fetuses [11-13]. It was found that 5 per cent of the pregnant women that participated in this research were not wearing their seatbeltatallduring pregnancy. These women felt unsafe or vulnerable using the seat belt during pregnancy; so they took uninformed action and stopped using the seat belt. Previous research $[9,12]$ suggests that not wearing the seat belt increases women's risk of injury, which is the opposite of their intentions. The capacity of the seat belt to accommodate the changing size and shape of pregnant women comfortably is an important safety issue since this can be the determining factor for women and their fetuses to be protected by the seat belt.

\subsection{Problems identified through the questionnaire}

The DFT UK guidelines state that 'the lap strap should go across the hips, fitting comfortably under the bump, while the diagonal strap should be placed between the breasts and around the bump' [7]. The 
women reported three main problems with wearing the seat belts in pregnancy. These problems were as follows.

1. The belt will not fit underneath the abdomen or tends to ride upwards on to the abdomen (24.4 per cent).

2. The belt is too tight on the abdomen, hips, and/or breasts (26.2 per cent).

3. The belt cuts into the breasts, shoulders, and/or neck (26.2 per cent).

The problems of tightness (problem 2) and cutting (problem 3) reveal that the seat belts were not positioned according to the guidelines since the belt was not expected to be positioned on the breasts nor on the abdomen, butbetween the breasts and underneath the abdomen [7]. This fact is further supported by women's choice of seat belt positioning later in the questionnaire. The other problems reported were difficulty with adjustment (13.7 per cent) and fastening (7.3 per cent), and the fact that the belt is too short (2.2 per cent). Figure 2 provides a summary for these ratios.

The tendency for the belt to ride upwards on to the abdomen is greatest in the second and third trimesters. This problem represents 5, 29, and 24 per cent of all the reported seat belt problems in the first, second, and third trimesters respectively. In the seated posture the increased abdominal depth of pregnancy causes the base of the abdomen to make contact with the upper thighs. Some pregnant women reported that this contact caused them difficulty in sliding the seat belt between the thighs and abdomen, hence preventing them from putting the lap belt into the correct position across the hips. Other women in the third trimester reported that, once they had positioned the lap belt across their hips and underneath the abdomen, their larger abdomen was beneficial in helping to hold the lap portion of the seat belt more securely in place and preventing it from sliding up on to the abdomen. Many pregnant women took action to prevent the belt ridingupwards on to the bumpwith the purpose of protecting the fetus or improving comfort. One method was to use an add-on device to hold the seat belt in position across their hips and the other method was to hold the belt away from the bump with their hands or thumbs. Similarly, more women were holding the belt away from their neck because it was cutting or rubbing them. The women were not aware that slack in the belt could prevent its proper functioning, hence increasing the risk of injury. Women modified their seat belt behaviour for protection or comfort but in reality put themselves at greater risk of injury, reinforcing the need to provide comfort for pregnant women for their safety.

The pregnant women were asked how they position the shoulder and lap sections of the seat belt. It has been revealed that only 13 per cent of the pregnant women had the entire seat belt correctly positioned in accordance with the DFT guidelines. The high level of incorrect belt positioning during pregnancy arises in some cases because the pregnant woman is unaware of the correct positioning. Alternatively many pregnant women explained that they understood how the seat belt should be positioned, but that it would not fit around the pregnant body correctly. The various seat belt positions are shown in Fig. 3 with the correct positions highlighted for both the shoulder and the lap portions of the belt.

Considering only the shoulder section, over half of the women had the seat belt in incorrect positions. The belt passing between the breasts and around the abdomen, i.e. the correct position, was used by 49 percent of the women. However, a variety of other shoulder belt positions were reported, including across one breast and over the abdomen 19 per cent, above both breasts and cutting the neck 15 per cent, off the shoulder 12 per cent, and not worn 5 per cent.

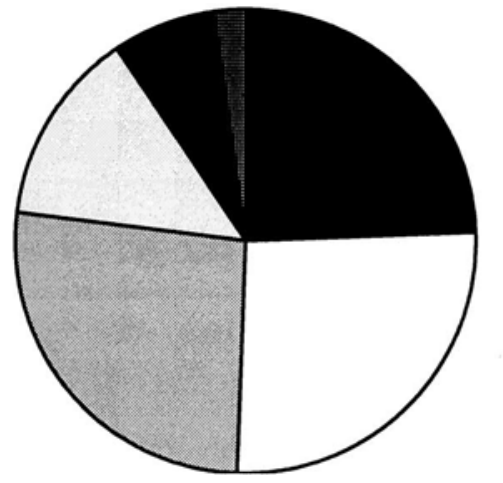

Won't fit under bump or rides up onto bump $\square$ Belt is too tight on abdomen, hips and/or chest $\square$ Cuts into shoulder, neck and/or breasts $\square$ Difficult to adjust Difficult to fasten/unfasten Not long enough

Fig. 2 Seat belt problems experienced by pregnant women 


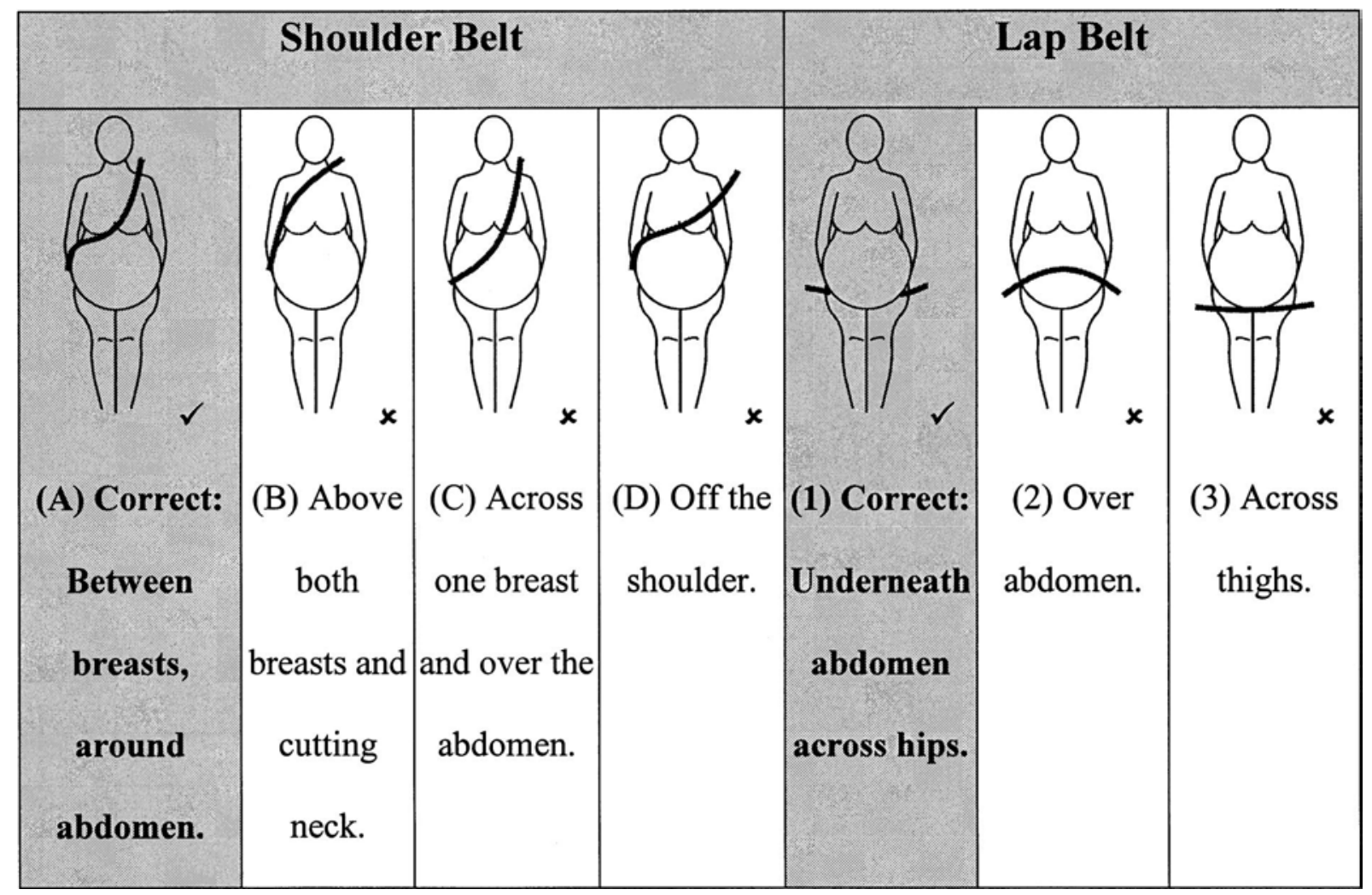

Fig. 3 Diagrams of different shoulder and lap belt positions with correct positions highlighted according to reference [7]

Regarding the lap portion of the seat belt, only 23 per cent of the women were wearing the lap belt correctly positioned across the hips; 45 per cent of the pregnant women had the lap belt over the bump, 26 per cent of the women had the lap belt across their thighs, and 6 per cent were not wearingitatall.

\subsection{Anthropometric measurements and needs identification}

The comfort and fit problems with the seat belt were also explained by the changing size and shape of the pregnant women. These problems can be addressed by ensuring that the needs of the pregnant women of all shapes and sizes are accommodated by the seat belt through all stages of pregnancy. This is particularly important in the third trimester when the size and shape of pregnant women are transformed to a great extent. Values for hip, abdominal, and chest region measurements are given for pregnant women in the third trimester in Table 2.

The abdominal region is where the most dramatic and obvious physical changes occur during pregnancy. Initial uterine growth is mainly in the lower abdomen; so the lower abdomen may contact with the upper thighs as it grows, causing difficulty for pregnant women in fitting the lap belt between the lower abdomen and upper thighs into the correct position across the hips. As the abdomen enlarges, it grows in many directions: out from the body in an anterior direction, lateral growth at either side of the abdomen, and upward growth as the enlarging fetus pushes the internal organs upwards. As pregnancy progress, the multi-directional growth means that the abdominal point moves upwards as in Fig. 4. However, the increased abdominal protrusion in the anterior direction means that the lower abdomen still remains in contact with the thighs, and the region of contact may increase, as shown in Fig. 5. The multidirectional growth also means that the abdomen will stretch the seat belt further than normal, particularly at the side and top of the abdomen, and extra belt length may be needed.

It is also important to consider the often ignored facts such as increase in hip size and the chest region (due to preparation for the birth and breast feeding). Some pregnant women reported that the seat belt was painfully tighton the breasts orwas notlong enough to fasten. The breasts are also pushed upwards (until the very last stages of pregnancy) by the enlarging 
Table 2 Percentages of the sample of pregnant women measured in the third trimester who would be excluded by a design based on the 95 th percentile UKanthropometric data for females (non-pregnant) and males

\begin{tabular}{lllll}
\hline & & \multicolumn{2}{c}{ Third trimester pregnant women } \\
\cline { 3 - 5 } \cline { 3 - 5 } $\begin{array}{l}\text { Measurement } \\
(\mathrm{mm})\end{array}$ & $\begin{array}{l}\text { Non-pregent } \\
\text { UK females [28] }\end{array}$ & Mean & $\begin{array}{l}\text { Excluded } \\
\text { by DBF } \\
(\%)\end{array}$ & $\begin{array}{l}\text { Excluded } \\
\text { by DBM } \\
(\%)\end{array}$ \\
\hline $\begin{array}{llll}\text { Hip circumference standing } \\
\text { Hip circumference sitting }\end{array}$ & 1037 & 1155.1 & 49 & 45 \\
Abdominal circumference standing & 840.6 & 1249.8 & $73 \dagger$ & $71 \dagger$ \\
Abdominal circumference sitting & $*$ & 1136.7 & 95 & 66 \\
Abdominal depth & 269.9 & 1161.3 & $97 \dagger$ & $89 \dagger$ \\
Chest circumference standing & 1007.8 & 359.5 & 62 & 65 \\
Chest circumference sitting & $*$ & 1046.5 & 9 & $*$ \\
Chest depth & 271.8 & 1072.3 & $16 \dagger$ & $*$ \\
\hline
\end{tabular}

DBF, design based on the 95th percentile data for non-pregnant UK females [28]; DBM, design based on the 95th percentile data for UK males [28].

* UK data not available in reference [28].

$\dagger$ UK data are not available for sitting posture in reference [28] and so comparison is made against data for the standing posture instead.

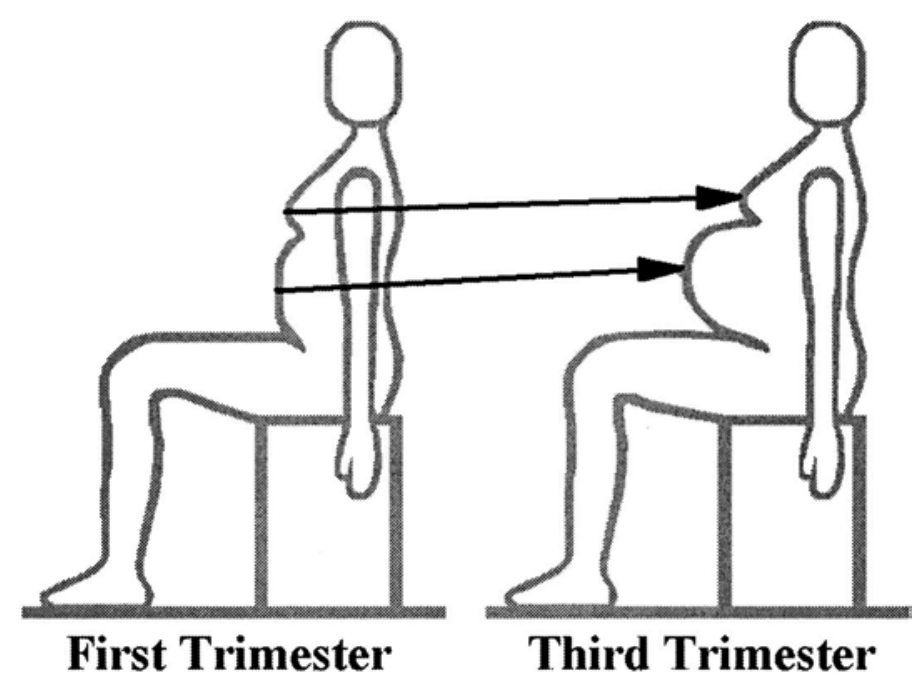

Fig. 4 Diagram showing abdominal growth pushing the breasts upwards as pregnancy progresses from the first trimester to the third trimester

abdomen, which decreases the space between the top of the abdomen and the base of the breasts. This introduces difficulty in fitting the seat belt between the breasts and abdomen.

Pregnant women experience size changes that make it vital to consider their needs as a separate user group, as proven by the marked size increases. For example the mean standing abdominal circumferencefor the pregnant women in the third trimester is $1136.7 \mathrm{~mm}$ and is significantly larger $(\mathrm{p}<0.000$ 02) than the value for non-pregnant women given in reference [28], and the mean abdominal depth of $359.5 \mathrm{~mm}$ is also significantly $(\mathrm{p}<0.03)$ larger. Increases in size in the chest and hip regions are also large. For example the mean standing hip circum- ference is $1155.1 \mathrm{~mm}$ for women in the third trimester and is $118.1 \mathrm{~mm}$ larger than for anthropometric data on non-pregnant women.

Comparison on the standing and seated measurements of the abdomen, hip, and chest circumferences reveals that seated sizes are much larger, and therefore using standing measurements is inadequate in vehicle design where the occupant is seated. For example the mean sitting hip circumference is $1249.8 \mathrm{~mm}$, which is $94.6 \mathrm{~mm}$ larger than the standing posture. This is also true for measurements of abdominal and chestcircumferences.

It is particularly important that these physical changes do not take place in isolation, and the interactions between the abdomen and breasts, and 


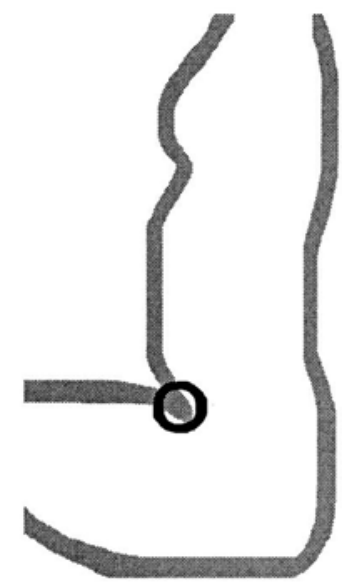

First Trimester

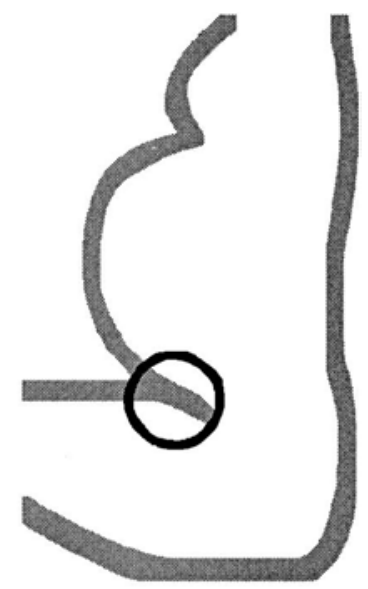

Third Trimester
Fig. 5 Diagram illustrating the increasing area of contact while seated between the thighs and lower abdomen as pregnancy progresses from the first trimester to the third trimester

between the abdomen and thighs, must be checked in detail during seat belt design to ensure correct fit of the seat belt.

The waistline disappears as the abdomen grows. Instead of the standard anthropometric measurement of waist height (the point of minimum circumference), the abdominal height (height of maximum abdominal circumference) was measured since this point could be at greatest risk of injury in a collision.

\section{STEERING WHEEL CLEARANCE PROBLEMS}

Current DFT guidelines recommend that the 'distance between the centre of the steering wheel to the breastbone should be at least 10 in $(25 \mathrm{~cm})^{\prime}$ [7]. However, the advice given is not specific to pregnant women. The NHTSA in the USA [8] advise pregnant women to sit as far back as possible from the steering wheel or dashboard and recommends a distance between the breastbone and the steering wheel or dashboard to be at least 10 in in order to reduce the possibility of injury from an inflating airbag in an accident. No recommendations for pregnant women have been found to date for the side impact airbags.

The significant abdominal protrusion occurring during pregnancy (as described in section 3.2) means that a large proportion of the pregnant women currently have their abdomen very close to the steering wheel; 86 per cent of the pregnant participants were seated at less than $25 \mathrm{~cm}$ away from the steering wheel, and this increased to 92 per cent for women in the third trimester. Some of the pregnant women were seated with less than $2.5 \mathrm{~cm}$ between their bump and the steering wheel, or with their bump in contact with the steering wheel during driving. The proximity of the enlarged abdomen to the steering wheel should be addressed since it is experienced by a large majority of the pregnant drivers.

Half of the pregnant women who completed the questionnaire believed that they or their fetus were at risk of injury from a deployed airbag. The majority of these women stated that they were concerned about the force or impact of the airbag against the abdomen and whether this would injure the child. Further research and data are needed to establish the level of risk to a pregnant woman and her fetus from deployed airbags. Some pregnant women had chosen to cease driving in pregnancy because of proximity to the steering wheel and fear that the fetus could be injured in an accident. A large group of the pregnant women said they increase the distance between their abdomen and the steering wheel by moving the seat slightly rearwards, and several participants also leant their seat back in addition; however, as expected, these women reported difficulty in reaching and operating the pedals.

\section{ANALYSISOFTHEDATA}

Statistical analysis of the anthropometric measurements of pregnant women confirms that the changes in pregnant women are not limited to the abdominal area. Significant increments are noted during pregnancy in hip circumference, chest depth, and chest circumference, as well as abdominal depth and the more commonly measured parameter of abdominal circumference.

The relevant anthropometric data in Table 2 reveals that any design based on the non-pregnant data available in the literature could ignore the physical features of a large proportion of pregnant women in the third trimester. The questionnaire results showed that a large group of pregnant women modify their use of seat belt behaviour because of fear and discomfort, hence putting themselves at greater risk of injury. Integrating these two sets of evidence suggests that it would be a valuable contribution to provide specific design for pregnant women for their assurance and comfort, and hence for their safety.

The 95th percentile value of non-pregnant female data and 95th percentile male data are compared with the pregnant women data measured in third trimester. A design that uses 95th percentile nonpregnant female data or male anthropometric data would exclude 45-97 per cent of pregnant women in the third trimester of pregnancy for all the hip and 
abdomen dimensions listed in Table 2. For example, the 95th percentile value for standing abdominal circumference of a non-pregnant female is $957.2 \mathrm{~mm}$ [28]. This is equivalent to only the fifth percentile abdominal circumference value for the pregnant women measured in the third trimester of pregnancy. Thus 95 per cent of pregnant women in the third trimester would not be accommodated by a design that used anthropometric data of a non-pregnant female for the abdominal circumference. More crucially the 95 th percentile abdominal circumference value for UK males is only equivalent to the 34th percentile abdominal circumference for pregnant women measured in the third trimester. Therefore even the design for large men using the 95 th percentile might not accommodate the enlarged abdomen of the pregnant women, and two-thirds of this sample of

pregnant women would be excluded. The exclusion rates are given in Table 2 for the other dimensions, including hip circumference, abdominal depth, chest depth, and chest circumference.

The concern is even greater when the measurements in the relevant seated posture for automotive design are considered. The sitting abdominal circumference data is not available in reference [28]. Any designs that use the standing abdominal circumference data for a non-pregnant female or male would exclude 97 per cent and 89 per cent respectively of pregnant women measured in the third trimester.

Comparing the maximum values, or extreme cases, against typical non-pregnant measurements gives far more dramatic results. The maximum standing hip circumference of $1475 \mathrm{~mm}$ is $317.7 \mathrm{~mm}$ larger than the 95th percentile value for non-pregnant UK females in reference [28]. In seated posture the difference is even greater at $516.7 \mathrm{~mm}$.

Similarly the maximum standing abdominal circumference measured was $1410 \mathrm{~mm}$ from a woman in her third trimester. This is $452.8 \mathrm{~mm}$ larger than the 95th percentile value for a non-pregnant female. The maximum sitting abdominal circumference of $1454 \mathrm{~mm}$ was nearly half a metre larger than the 95th percentile value for a non-pregnant women, demonstrating the remarkable range in abdominal size in the pregnant population.

\section{DESIGNGUIDELINES}

Comparing the anthropometry of pregnant women against the data for non-pregnant females and males shows the significance of considering pregnant women as a separate user group. Anthropometric data from a relevant posture, e.g. sitting sizes rather than standing, is important. The awareness of the extreme cases that can occur because of growth during pregnancy is also essential.

This study reveals that, because of the incorrect seat belt positioning rate, 87 per cent of the pregnant women in our sample could be inadequately protected by their seat belt and 92 per cent of them in their third trimester were sitting too close to the steering wheel.

The analysis of the questionnaire and the anthropometric measurements are used to generate the following guidelines for the designers in the automotive industry to assist them in considering the features of pregnant women at the design stage.

The authors recommend the following.

\section{Accommodating pregnant occupant anthropometry}

A1. Anthropometric measurements of the pregnant population, similar to those provided in this research, should be included as opposed to nonpregnant population anthropometry. As represented by this sample, the bodies of pregnant women are significantly different from those of non-pregnant females and therefore have different geometric considerations during design. This could be especially important if the type of car is designed for and expected to be used by women of childbearing age.

A2. Pregnant women should be considered as a separate user group during vehicle design in order to attend to their particular safety needs and requirements.

A3. Women from various stages of pregnancy should be considered, especially anthropometric measurements of the pregnant women from the last trimester of pregnancy when the abdomen is at greatest risk of injury.

A4. Anthropometric measurement data should be taken from the relevant posture, i.e. specifically seated posture measurements for use in car design. The standing and seated measurements taken from this sample show large differences, and using standing data in seat design could exclude larger portions of the seated population than intended.

\section{Seat belt design}

B1. A specific adaptable integrated seat belt should be designed to make certain that it is more suitable for the pregnant body, so that pregnant women can comfortably fit the belt and are safely restrained during all stages of pregnancy. 
This could help toincrease the number of women wearing the seat belt in the correct position.

B2. Specific areas of concern for the seat belt are the changes in the hips, abdomen, and chest regions. Also the region between 'the breasts and the top of the pregnant abdomen' and the interactions between 'the base of the abdomen and upper thigh area'should be checked in detail.

B3. Anthropometric measurements from pregnant women for the necessary belt length should be used in order to ensure that the seat belt accommodates the enlarged hips, abdomen, and chest area during all stages of pregnancy. (This will also benefit the group of obese people.)

\section{Steering wheel clearanceprovision}

$\mathrm{C} 1$. Anthropometric measurements from pregnant women should be used to give practical advice on keeping a safe distance away from the steering wheel in order to reduce the impact of the steering wheel or deployed airbags in case of an accident.

C2. A greater range of fore and aft seat adjustments should be provided. This would allow pregnant women to move their seats rearwards to compensate for the enlarging abdomen. However, it is important to consider the pregnant woman and the car environment as a system and hence the provision of fore and aft adjustable pedals or pedal extenders would greatly benefit pregnant women. Adjustable pedals have been found to be effective in increasing both chest-to-steeringwheel and abdomen-to-steering-wheel distances [30] in a sample of males and non-pregnant females. Adjustable or extendable pedals would allow pregnant women to move their seats rearwards but also be able comfortably to reach and operate the pedals to drive. (This will also benefit the group of small-stature people.)

C3. A retractable steering wheel should be provided so that the steering wheel can be moved further away from the abdomen as it enlarges. Automotive designers could check reach capabilities of pregnant women, using the anthropometric data provided, for all parts of the car with the seat in all fore and aft positions to ensure that pregnant women can reach the pedals, and all other controls.

\section{Vehicle design}

D1. The possibility of new and alternative methods of driving, such as drive-by-wire, should be con- sidered to remove the risk of impact with the steering wheel.

D2. Pregnant women (ideally from various stages of pregnancy) should be involved in user comfort tests with prototype vehicles to check that pregnant women are accommodated in reality.

\section{Educating pregnant women}

E1. A broad publicity campaign of advice should be undertaken to target pregnant women. The automotive industries could help by providing leaflets or information in car manuals about seat belt position in pregnancy to help to increase awareness levels about belt positioning and consequently to provide better protection against injury. Automotive industries could also train all staff in contact with the public to advise pregnant women correctly about seat belt positioning.

E2. The publicity campaign could be supported by inclusion of the DFT [7] or NHTSA [8] guidelines into road regulations by the appropriate transport authorities. For example, seat belt requirements and advice about children in cars are currently included in The Highway Code [31] for the UK, and seat belt positioning information for pregnant women would complement these instructions. Similarly all learner drivers must learn the guidelines and consequently improve awareness about seat belts in pregnancy and increase numbers of pregnant women that use the seat belt in the correct position.

E3. Pregnant women are advised to travel as a passenger instead of driving, or to choose alternative means of transport, if they feel that their car safety is compromised by pregnancy. Women should consider their proximity to the steering wheel and whether they are able to position the seat belt correctly according to government guidelines [7].

E4. Women should be advised about the safety tests and any possible changes in insurance cover for all the products marketed for a pregnant occupant.

\section{CONCLUSIONS}

This research identified the problems of pregnant car occupants through 450 responses to a questionnaire and 100 sets of anthropometric measurements from pregnant women. The analysis of measurements data is used to confirm the problems by identifying 
excluded populations during a typical design process. The design guidelines are drawn up to assist automotive designers and hence to improve the quality of life of pregnant women. The focus of this paper is on automotive design, and improvements for the safety of pregnant car occupants; however, as a by-product it may also be useful in other areas of product design for pregnant women in general and contribute to improving design for obese people too.

This research has shown that a wide variety of

physical changes that women undergo during pregnancy can have an impact upon the safety of pregnant women during car travel. Because of the anthropometric changes during pregnancy the two major areas of concern for the safety of pregnant vehicle occupants are seat belt positioning and steering wheel clearance. Some pregnant women ignore

the benefits of wearing the seat belts properly because of discomfort and fear. However, some were unaware of the recommended positioning during pregnancy. Most feared proximity to the steering wheel and could not do anything about it.

This research revealed that only 13 per cent of the pregnant women who took part in this study had the entire seat belt correctly positioned in accordance with the DFT guidelines. Similarly 92 per cent of the pregnant participants in the third trimester were seated less than $25 \mathrm{~cm}$ away from the steering wheel in contrast with the recommendations.

The most important recommendation to automotive designers is to use anthropometric data of pregnant women, similar to the data provided in this research, to check that designs can accommodate pregnant women safely and to address the problems identified through the questionnaire.

The present authors' general recommendations included the design of new adaptable integrated seat belts, and the use of anthropometric measurements of pregnant women to ensure comfort issues. The The 'Automotive design: incorporating the needs of capacity of the seat belt to accommodate the changing pregnant women' project is funded by the EPSRC size and shape of pregnant women comfortably is GR/R13081 research grant of the Innovative Manuan important safety issue since this can be the determining factor for women and their fetuses to be protected by the seat belt.

Specific recommendations included the attention required in changes in hip, abdominal, and chest areas, the related length of the seat belts, the provision of a greater range of fore and aft seat adjust-

ments, adjustable or extendable pedals, drive-by-wire, and retractable steering wheels. Comfort tests with pregnant women and broad publicity for the proper use of seat belts and safe sitting positions are also recommended.
The high level of significance in the difference between pregnant and non-pregnant women meant that it is crucial to consider pregnant women as a separate user group during vehicle design in order to attend to their particular safety needs. This research also revealed that any design based on the non-pregnant data available in the literature could ignore the physical features of a large proportion of pregnant women in the third trimester. Consideration of the interaction between local changes in the pregnant body is also highlighted for better designs.

In this research it has been shown that a majority of the pregnant population in the third trimester can be excluded in designs based on a typical 95th percentile of male or non-pregnant female populations. The exclusion was much more dramatic in extreme cases of measurements. This provided understanding of the complaints and discomfort of pregnant women. The research also highlighted the difference between measurements taken from the standing and seated postures of pregnant women for use in vehicle design. for accidental death for pregnant women and their fetuses. Earlier research has proven that wearing the seat belt and ensuring that it is correctly positioned are of vital importance to the safety of pregnant women and their fetuses. Therefore evidence suggests that following the DFT advice and placing the lap strap across the hips, fitting under the bump, while placing the diagonal strap between the breasts and around the bump even if it is not comfortable, seems to be the best available advice to take until new adjustable integrated designs are available.

\section{ACKNOWLEDGEMENTS} facturing and Construction Research Centre. The authors wish to express their thanks to sponsors, to collaborating car manufacturers, to consultant obstetrician and gynaecologist M. Griffiths, to all pregnant women who have participated in this research, and to the referees for their recommendations.

\section{REFERENCES}

1 Baerga-Varela, Y., Zietlow, S., Bannon, M., Harmson, W., and Ilstrup, D. Trauma in pregnancy. Mayo Clinic Proc., 2000, 75(12), 1243-1248.
Road traffic accidents form the largest cause 
2 Cosi, P. R., Rasslan, S., Bechelli de Oliveira, L., Kronfly, F.S., and Marinho, V.P.Trauma in pregnant women: analysis of maternal and fetal mortality. Injury, 1999, 30, 239-243.

3 Wiechel, J. F., Sens, M. J., and Guenther, D. A. Critical review of the use of seat belts by pregnant women. SAE Report 890752, Society of Automotive Engineers, Warrendale, Pennsylvania, USA, 1989.

4 Goodwin, T. M. and Breen, M. T. Pregnancy outcome and fetomaternal hemorrhage after noncatastrophic trauma. Am. J. Obstet. Gynec., 1990, 162(3), 665-671.

5 Pearlman, M. D., Tintinalli, J. E., and Lorenz, R. P. A prospective controlled study of outcome after trauma during pregnancy. Am. J. Obstet. Gynec., 1990, 162(6), 1501-1510.

6 Pearlman, M. D. Motor vehicle crashes, pregnancy loss and preterm labor. Int. J. Gynec. Obstet., 1997, 57, 127-132.

7 Department for Transport, Seat belts and child restraints. DFT Leaflet T/INF/251, Department for Transport, London, 2003.

8 National Highway Traffic Safety Administration, Should pregnant women wear seatbelts? NHTSA Leaflet DOT HS 809 506, National Highway Traffic Safety Administration, Washington, DC, USA, September 2002

9 Pearlman, M. D. and Viano, D. C. Automobile crash simulation with the first pregnant crash test dummy. Am. J. Obstet. Gynec., 1996,175(4), 977-981.

10 Bunai, Y., Nagai, A., Nakamura, I., and Ohya, I. Fetal death from abruptio placentae associated with incorrect use of a seat belt. Am. J. Forensic Med. Pathology, 2000, 21(3), 207-209.

11 Crosby, W. M., Snyder, R. G., Snow, C. C., and Hanson, P. G. Impact injuries in pregnancy. Am. J. Obstet. Gynec., 1968,101(1), 100-110.

12 Viano, D., Jedrzejczak, E., Deng, B., Smrcka, J., Kempf, P., and Pearlman, B. Belt and airbag testing with a pregnant hybrid III dummy. J. Traffic Medicine, 1996, 26(3-4), 125-138.

13 Klinich, K. D., Schneider, L. W., Moore, J., and Pearlman, M. D. Investigations of crashes involving pregnant occupants. In Proceedings of the 44th Meeting of the Association for the Advancement of Automotive Medicine, Chicago, Illinois, USA, 2-4 October 2000, pp. 37-55.

14 Johnson, H. C. and Pring, D. W. Car seatbelts in pregnancy: the practice and knowledge of pregnant women remain causes for concern. Br. J. Obstet Gynaec., 2000, 107, 644-647.

15 Griffiths, M., Usherwood, M. M., and Reginald, P.W. Antenatal teaching of the use of seat belts in pregnancy. Br. Med. J., 1992, 304(6827), 614.

16 Phillips, M. E. Maternal knowledge, attitude, and practice of three motor vehicle safety belt behaviors during pregnancy. In Proceedings of the International Health Promotion Conference, Brunel University, West London, April 1995, pp. 158-161.
17 Wallace, C. General practitioners'knowledge of and attitudes to the use of seat belts in pregnancy. Ir. Med. J., 1997, 90(2).

18 Acar, B. S. and Weekes, A. M. Pregnant driver behaviour and safety. In Proceedings of the International Conference on Driver Behaviour and Training, Stratford-upon-Avon, 11-12 November 2003, pp. 125-133 (Ashgate, Aldershot, Hampshire).

19 Klinich, K. D., Schneider, L. W., Moore, J., and Pearlman, M. D. Injuries to pregnant occupants in automotive crashes. UMTRI Report 98-SP-P-17, University of Michigan Transportation Research Institute, Ann Arbor, Michigan, USA, 1998.

20 DeLeonardis, D. M., Ferguson, S. A., Pantula, J. F. Survey of driver seating position in relation to the steering wheel. SAE Report 980642, Society of Automotive Engineers, Warrendale, Pennsylvania, 1998.

21 Dobson, W. J. and Baird, J. A. Driver height related to seat position under driving conditions. Accid. Reconstr. J., 1996, 52-53.

22 Pearlman, M. D., Klinich, K. D., Schneider, L. W., Rupp, J. D., Moss, S., and Ashton-Miller, J. A comprehensive program to improve safety for pregnant women and fetuses in motor vehicle crashes: a preliminary report. Am. J. Obstet. Gynec., 2000, 182(6), 1554-1564.

23 Schneider, L. W., Klinich, K. D., Rupp, J. D., Moore, J., Eby, B., and Ashton-Miller, J. Improving Automotive Safety During Pregnancy. UMTRI Res. Rev., 2000, 31(1), 1-11.

24 Aschkenazi, S., Kovanda, J., Stingl, J., Karl, J., and Schoenfeld, A. Airbags: benefits and risk in the pregnant population. Int. J. Risk Safety Medicine, 1998, 11, 85-91.

25 Klinich, K. D., Schneider, L. W., Rupp, J. D., Eby, B., and Pearlman, M. D. Challenges in frontal crash protection of pregnant drivers based on anthropometric considerations. In Occupant Protection, 1999, pp. 105-1119 (Society of Automotive Engineers, Warrendale, Pennsylvania).

26 Yamana, N., Okabe, K., Nakano, C., Zenitani, Y., and Saita, T. The body form of pregnant women in monthly transitions. Jap. J. Ergonomics, 1984, 20(3), 171-178.

27 Pheasant, S. Bodyspace: Anthropometry, Ergonomics, and Design, 1986 (Taylor \& Francis, London).

28 Department of Trade and Industry. Adultdata: The Handbook of Adult Anthropometric and Strength Measurements - Data for Design Safety, 1998 (Department of Trade and Industry, London).

29 Menon, K. R., Al-Mukhtar, A., and Aldoori, M. I. Minerva. Br. Med. J., 2002, 324, 1166.

30 Parenteau, C. S., Shen, W., and Shah, M. The effectiveness of adjustable pedals usage. In Proceedings of the SAE 2000 World Congress, Detroit, Michigan, USA, 6-10 March 2000 (Society of Automotive Engineers, Warrendale, Pennsylvania).

31 Driving Standards Agency. The Highway Code, 1999 (HM Stationery Office, London). 